\title{
Exploring the determinants of ethnic differences in insulin clearance between men of Black African and White European ethnicity
}

\author{
Meera Ladwa ${ }^{1}$. Oluwatoyosi Bello ${ }^{1}$. Olah Hakim ${ }^{1} \cdot$ Maria Linda Boselli $^{2} \cdot$ Fariba Shojaee-Moradie $^{3}$. \\ A. Margot Umpleby ${ }^{3}$. Janet Peacock ${ }^{4}$. Stephanie A. Amiel ${ }^{1} \cdot$ Riccardo C. Bonadonna $^{5} \cdot$ Louise M. Goff $^{1}$ (B)
}

Received: 27 August 2021 / Accepted: 3 October 2021 / Published online: 18 October 2021

(c) The Author(s) 2021

\begin{abstract}
Aim People of Black African ancestry, who are known to be at disproportionately high risk of type 2 diabetes (T2D), typically exhibit lower hepatic insulin clearance compared with White Europeans. However, the mechanisms underlying this metabolic characteristic are poorly understood. We explored whether low insulin clearance in Black African (BA) men could be explained by insulin resistance, subclinical inflammation or adiponectin concentrations.

Methods BA and White European (WE) men, categorised as either normal glucose tolerant (NGT) or with T2D, were recruited to undergo the following: a mixed meal tolerance test with C-peptide modelling to determine endogenous insulin clearance; fasting serum adiponectin and cytokine profiles; a hyperinsulinaemic-euglycaemic clamp to measure whole-body insulin sensitivity; and magnetic resonance imaging to quantify visceral adipose tissue.

Results Forty BA (20 NGT and 20 T2D) and 41 WE (23 NGT and 18 T2D) men were studied. BA men had significantly lower insulin clearance $(P=0.011)$ and lower plasma adiponectin $(P=0.031)$ compared with WE men. In multiple regression analysis, ethnicity, insulin sensitivity and plasma adiponectin were independent predictors of insulin clearance, while age, visceral adiposity and tumour necrosis factor alpha (TNF- $\alpha$ ) did not significantly contribute to the variation.

Conclusion These data suggest that adiponectin may play a direct role in the upregulation of insulin clearance beyond its insulin-sensitising properties.
\end{abstract}

Keywords Insulin clearance $\cdot$ Adiponectin $\cdot$ Ethnicity $\cdot$ African $\cdot$ Type 2 diabetes $\cdot$ Inflammation

Managed by Massimo Porta.

Louise M. Goff

louise.goff@kcl.ac.uk

1 Diabetes Research Group, Department of Nutritional Sciences, Faculty of Life Sciences and Medicine, School of Life Course Sciences, King's College London, Franklin-Wilkins Building, Room 3.87, Waterloo Campus, London SE1 9NH, UK

2 Division of Endocrinology and Metabolic Disease, University of Verona School of Medicine, Verona, Italy

3 Faculty of Health and Medical Sciences, University of Surrey, Guildford, UK

4 Department of Epidemiology, Geisel School of Medicine, Dartmouth College, Hanover, NH, USA

5 Department of Medicine and Surgery, University of Parma and Azienda Ospedaliera Universitaria di Parma, Parma, Italy

$\begin{array}{ll}\text { Abbreviations } \\ \text { BA } & \text { Black African(s) } \\ \text { BMI } & \text { Body mass index } \\ \text { HbA1c } & \text { Glycated haemoglobin } \\ \text { IFN-y } & \text { Interferon gamma } \\ \text { IL } & \text { Interleukin } \\ \text { NGT } & \text { Normal glucose tolerance } \\ \text { OGTT } & \text { Oral glucose tolerance test } \\ \text { T2D } & \text { Type 2 diabetes } \\ \text { TNF-a } & \text { Tumour necrosis factor alpha } \\ \text { VEGF } & \text { Vascular endothelial growth factor } \\ \text { WE } & \text { White European(s) }\end{array}$

\section{Introduction}

A consistently recognised feature of physiology in Black African (BA) populations is low insulin clearance in comparison with White Europeans (WE), with studies indicating up to $74 \%$ lower insulin clearance in BA compared with WE 
subjects [1]. Modelling methods have found that this difference lies in hepatic, as opposed to extra-hepatic, insulin clearance [2].

Hepatic insulin clearance is predominantly mediated by binding of insulin to its receptor [3]; therefore, it is an integral part of insulin's action on the liver. Greater insulin sensitivity has been associated with greater clearance [4], including in BA populations [5]. Accordingly, as there is evidence that BA populations may be more insulin resistant compared with other ethnicities [6], it is believed that impaired insulin sensitivity drives their low insulin clearance [7].

However, an emerging counterargument proposes that low hepatic insulin clearance may not be purely compensatory, but a primary abnormality in the development of type 2 diabetes (T2D) [8, 9]. According to this hypothesis, defects in hepatic insulin clearance promote chronic hyperinsulinaemia, which in turn leads to insulin receptor desensitisation, target tissue insulin resistance and subsequent glucose intolerance. In this model, low hepatic clearance in certain ethnic groups is the a priori risk factor underlying their increased prevalence of T2D and precedes the development of insulin resistance. Supporting this hypothesis, insulin clearance has been identified as an important predictor of T2D development in longitudinal studies of African-Americans [10].

Thus, there is considerable interest in understanding the mechanisms underlying low insulin clearance in BA populations. If it occurs independently of insulin resistance, then alternative explanations must be sought. Chronic, low-grade inflammation may be a factor, with evidence that elevated C-reactive protein (CRP) [11], white cell counts [12] and plasminogen activator inhibitor 1 (PAI-1) levels [13] are associated with impaired insulin clearance. Ethnic differences in inflammatory profiles have been recognised, including higher levels of C-reactive protein and interferon gamma (IFN-y) in BA subjects [14, 15]; therefore, it is plausible that subclinical inflammation may account for the variation in hepatic insulin clearance rates observed in different ethnic groups.

Another possibility is that low insulin clearance is secondary to ethnic differences in concentrations of adiponectin, an adipokine which has numerous roles in glucose and lipid metabolism. Studies have consistently shown that BA subjects have lower plasma adiponectin levels compared with WE [16-18]. An association between adiponectin and hepatic insulin clearance has also been observed [19, 20], and the upregulation of liver adiponectin receptors is associated with greater hepatic insulin clearance in animal models [21]. However, to date, no studies have looked at the role of adiponectin in relation to insulin clearance in BA populations.

Therefore, the aim of this study was to assess ethnic differences in insulin clearance and explore its predictors - particularly insulin sensitivity, inflammatory biomarkers and adiponectin - in BA and WE men with normal glucose tolerance (NGT) and early T2D in a secondary analysis of the SouL-DeEP study [22].

\section{Materials and methods}

The data were collected as part of the South London Ethnicity and Diabetes Phenotyping study (SouL-DeEP). The SouL-DeEP study was an observational cross-sectional study aimed at exploring ethnic differences in a range of mechanisms underlying the development of T2D between men of WE and BA ethnicity with NGT and early T2D. The study was designed to enable the exploration of a wide range of hypotheses, several of which have been published [22-24]. Data collection took place between April 2013 and April 2019. The full protocol has been published [22].

Recruitment was carried out through advertising in local press and via primary care. Eligible participants were male, 18-65 years of age and with a body mass index (BMI) of $20-40 \mathrm{~kg} / \mathrm{m}^{2}$. Participants self-identified as either WE or BA. WE participants had four self-declared European grandparents with at least two of them of north-west European ancestry. BA participants had four self-declared grandparents from West African countries.

Eligible NGT participants had a fasting venous plasma glucose of $<6.1 \mathrm{mmol} / \mathrm{L}$ and a 2 -h OGTT glucose of $<7.8 \mathrm{mmol} / \mathrm{L}$. Eligible T2D participants had a diagnosis of T2D with a duration of $\leq 5$ years, treated with lifestyle measures and/or metformin monotherapy and a screening $\mathrm{HbA} 1 \mathrm{c} \leq 64 \mathrm{mmol} / \mathrm{mol}(8.0 \%)$. Exclusion criteria were: treated with other diabetes medications, steroids or betablockers; serum creatinine $>150 \mathrm{mmol} / \mathrm{l}$; serum alanine transaminase level $>2.5$-fold above the upper limit of the reference range; positive auto-antibodies for insulin, glutamic acid carboxylase (GAD) or islet antigen 2 (IA2); sickle cell disease (trait permitted); or any contraindication to magnetic resonance imaging.

\section{Endogenous insulin clearance}

Following an overnight fast, participants underwent a mixed meal tolerance test (MMTT). A cannula was inserted into an antecubital fossa vein; following sampling of fasting blood at -10 and $0 \mathrm{~min}$, participants consumed a specified volume of Ensure Plus milkshake drink (63\% carbohydrate, 22\% protein and 15\% fat) (Abbott Nutrition, UK) based on $6 \mathrm{cal}$ (4 ml) per kg body weight within a 5-min period. Further samples were drawn at 10, 20, 30, 40, 50, 60, 75, 90, 120, 150 and 180 min for assessment of glucose, C-peptide and insulin concentrations. The glucose and C-peptide curves were modelled to determine area under the curve of total 
endogenous insulin secretion over the 180-min duration $\left(\mathrm{AUC}_{\mathrm{ISR}}\right)$ [22], using SAAM-II 1.2 software (SAAM Institute, Seattle, Washington). Mean endogenous insulin clearance was then calculated according to the following formula:

Clearance $_{\text {Ins }}=\frac{\mathrm{AUC}_{\text {ISR }}}{\mathrm{AUC}_{I}+\left(I_{\text {Final }}-I_{\text {Basal }}\right) \cdot \mathrm{MRT}_{\text {Ins }}}$

where $\mathrm{AUC}_{\mathrm{I}}=$ area under the curve of insulin concentration, $\mathrm{I}_{\text {Final }}=$ insulin concentration at end of study, $\mathrm{I}_{\text {Basal }}=$ insulin concentration at start of study, $\mathrm{MRT}_{\text {ins }}=$ mean residence time of insulin.

For the purposes of this calculation, the $\mathrm{MRT}_{\mathrm{ins}}$ is taken as $18 \mathrm{~min}$ for non-diabetics and $27 \mathrm{~min}$ for diabetics as described in Navalesi et al. [25].

\section{Whole-body insulin sensitivity}

A 240-min two-step hyperinsulinaemic-euglycaemic clamp was conducted. Euglycaemia $(5.0 \mathrm{mmol} / \mathrm{l})$ was achieved using variable rate $20 \%$ (wt/vol) dextrose. Whole-body insulin sensitivity was assessed in the high-dose insulin phase: $40 \mathrm{mU} \mathrm{m}^{-2}$ BSA min ${ }^{-1}$. Blood was drawn at 150, 180, 210, 220, 230 and $240 \mathrm{~min}$ for the assessment of plasma glucose and insulin concentrations. Insulin sensitivity was quantified using the $\mathrm{M}$ value $\left(\mathrm{mg} \mathrm{m}^{-2} \mathrm{BSA} \mathrm{min}{ }^{-1}\right)$, which was measured during the final $30 \mathrm{~min}$ of the high-dose insulin phase of the clamp, calculated as total glucose disposal corrected for deviations in plasma glucose concentration. Whole-body insulin sensitivity was then expressed as $\mathrm{M} / \mathrm{I}$, the $\mathrm{M}$ value corrected for the steady-state insulin concentration during the last $30 \mathrm{~min}$ of the clamp $\left(\mathrm{mg} \mathrm{m}^{-2} \mathrm{BSA} \mathrm{min}^{-1}\right) /(\mathrm{pmol}$ $\left.\mathrm{L}^{-1}\right)$.

\section{Visceral fat}

A Dixon-based MRI sequence was used on a 1.5-Tesla Siemens scanner to obtain images from the neck to the knee (excluding arms). Three hundred and eighty-four contiguous, axial T1-weighted gradient-echo images with a slice thickness of $3 \mathrm{~mm}$ were acquired, from which fat and water images were produced as part of the Dixon sequence. MRI data were analysed using the open-source image analysis software HOROS V 1.1.7 (www.horosproject.org; accessed 21/10/2017) by a single analyst who was blinded to clinical data. Areas of visceral adipose tissue (VAT) were quantified from an axial MRI image at the L4-5 spinal anatomical position.

Assessments were performed in random order at the Clinical Research Facility, King's College Hospital, London, UK, while MRI imaging took place at Guy's Hospital, London, UK, with at least 7 days between visits.

\section{Laboratory analysis}

Plasma adipokines and cytokines were measured on fasting plasma taken during the MMTT assessment using immunoassays (Affinity Biomarker Labs, UK). Plasma total adiponectin was measured using Human Quantikine enzyme-linked immunosorbent assay (ELISA) kits (Bio-Techne, USA). Plasma TNF- $a$, IFN- $\gamma$, IL-6, IL-8, IL-10 and vascular endothelial growth factor (VEGF) were determined by electrochemiluminescence using a Human Proinflammatory multiplex immunoassay, Mesoscale Quickplex Discovery SQ120 (Meso Scale Discovery, USA). Plasma glucose concentrations were determined in duplicate using an automated glucose analyzer (Yellow Spring Instruments, 2300 STAT Glucose Analyzer, Ohio, USA). Plasma insulin concentrations were determined by immunoassay using chemiluminescent technology (ADVIA Centaur System, Siemens Healthcare Ltd., Camberley, UK). Plasma C-peptide concentrations were determined by radioimmunoassay (Millipore Ltd., Hertfordshire, UK).

\section{Statistics}

The study is a secondary analysis of the SouL-DeEP study which included 20 samples per ethnic group with type 2 diabetes to allow the detection of a difference of one standard deviation with power $90 \%$ and two-sided statistical significance 5\% in the primary outcome variable (first-phase insulin secretion determined from the hyperglycaemic clamp test).

Normality of continuous variables was determined by inspection of histograms and Shapiro-Wilkes test. Where variables significantly deviated from normality, log transformation was carried out to achieve a normal distribution prior to the use of parametric tests. Categorical variables were analysed using Fisher's exact test for ordinal data. A two-way between-group ANOVA was used to analyse the dependent variables of ethnicity and glucose tolerance on the outcome measures. Relationships between variables of interest were assessed with Pearson's correlation coefficient. Multiple linear regression models were built step-wise to explore the determinant of insulin clearance with covariates of ethnicity, age, BMI, insulin sensitivity, visceral fat, adiponectin and TNF- $a$ concentrations. As this study was a secondary analysis and exploratory, we have not adjusted for multiple testing. All analyses were conducted with SPSS, version 25.0.

\section{Results}

The clinical characteristics of the 40 BA (20 NGT and 20 T2D) and 41 WE (23 NGT and 18 T2D) participants are presented in Table 1 . The ethnic groups were similar overall in mean age, BMI, fasting glucose and $\mathrm{HbA1c}$. 
Insulin clearance, insulin sensitivity, adiponectin and inflammatory biomarker data, by ethnic group and glucose tolerance status, are presented in Table 2. There were no significant ethnic differences in insulin sensitivity across either glucose tolerance group. BA men had significantly lower mean endogenous insulin clearance (Fig. 1), plasma adiponectin and visceral adipose tissue compared with WE men. Mean IL-10 was higher in BA men. There were no significant ethnic differences in plasma TNF-a, IFN- $\gamma$, IL-6, IL-8 or vascular endothelial growth factor (VEGF) concentrations. Men with T2D had lower mean insulin sensitivity, insulin clearance and adiponectin but higher VAT, TNF- $a$, IL-8 and VEGF concentrations compared with NGT men.

Associations between insulin clearance and the adipocytokines for each ethnic group and the cohort as a whole are shown in Table 3. Plasma adiponectin was significantly correlated with insulin clearance in the cohort as a whole $(r=0.46, P<0.001)$, but when examined within ethnicity, the association was statistically significant in only BA men. TNF- $a$ was inversely correlated with insulin clearance in the cohort as a whole $(r=-0.24, P=0.037)$, but when examined within ethnicity, this was significant in only WE men (Table 3). There were no significant relationships found between insulin clearance and IFN-y, IL-6, Il-8, IL-10 or VEGF (Table 3). Multiple regression analysis showed that both ethnicity and adiponectin were significant predictors of insulin clearance in a mutually adjusted model that also included insulin sensitivity and BMI as covariates. In that model, the adjusted mean difference in insulin clearance in WE vs BA was $96 \mathrm{~mL} \mathrm{~m}^{-2}$ BSA min ${ }^{-1}$ (Table 4, Model 1).

The use of visceral fat in place of BMI as a marker of adiposity, and the addition of age and plasma TNF- $a$ as covariates, made no appreciable difference to the estimated effects of ethnic group ( 99 compared to $96 \mathrm{~mL} \mathrm{~m}^{-2}$ BSA $\left.\min ^{-1}\right)$. The effect of adiponectin was even greater in the fuller model and remained statistically significant (Table 4 , Model 2).

\section{Discussion}

The importance of insulin clearance as a modulator of peripheral insulin levels is increasingly recognised [26], particularly in BA populations who, in comparison with other ethnicities, have consistently been shown to exhibit a distinctly hyperinsulinaemic response to glucose, predominantly driven by relatively low insulin clearance [27]. Here, we have presented data which find that insulin clearance may be determined by ethnicity independently of insulin resistance, adiposity and subclinical inflammation and that plasma adiponectin may play a direct role in the upregulation of insulin clearance beyond its insulin-sensitising effects.

Table 1 Characteristics of study participants

\begin{tabular}{|c|c|c|c|c|c|c|c|c|}
\hline & \multicolumn{3}{|l|}{ BA } & \multicolumn{3}{|l|}{ WE } & \multirow[t]{2}{*}{$P$ (ethnicity) } & \multirow{2}{*}{$\begin{array}{l}P \text { (glucose } \\
\text { tolerance) }\end{array}$} \\
\hline & $\begin{array}{l}\text { All } \\
(n=40)\end{array}$ & $\begin{array}{l}\text { NGT } \\
(n=20)\end{array}$ & $\begin{array}{l}\text { T2D } \\
(n=20)\end{array}$ & $\begin{array}{l}\text { All } \\
(n=41)\end{array}$ & $\begin{array}{l}\text { NGT } \\
(n=23)\end{array}$ & $\begin{array}{l}\text { T2D } \\
(n=18)\end{array}$ & & \\
\hline Age (years) & $43.4(15.0)$ & $32.4(12.1)$ & $54.4(7.7)$ & $44.4(15.1)$ & $35.9(13.9)$ & $55.8(6.8)$ & 0.307 & $<0.001$ \\
\hline Weight (kg) & $88.7(13.0)$ & $85.0(13.4)$ & $92.4(11.8)$ & $92.2(17.9)$ & $86.5(16.5)$ & $99.8(17.2)$ & 0.182 & 0.003 \\
\hline $\operatorname{BMI}\left(\mathrm{kg} / \mathrm{m}^{2}\right)$ & $28.4(3.8)$ & $26.9(3.5)$ & $30.0(3.5)$ & $28.5(5.0)$ & $26.5(4.6)$ & $31.3(4.2)$ & 0.612 & $<0.001$ \\
\hline Fasting glucose (mmol/ L) & $5.9(1.1)$ & $5.1(0.5)$ & $6.7(1.0)$ & $6.0(1.3)$ & $5.2(0.4)$ & $7.0(1.3)$ & 0.381 & $<0.001$ \\
\hline $\mathrm{HbA1c}$ IFCC (mmol/mol) & $44.0(9.2)$ & $37.5(5.2)$ & $50.4(7.8)$ & $41.6(8.6)$ & $35.9(2.9)$ & $49.2(7.8)$ & 0.321 & $<0.001$ \\
\hline HbA1c (DCCT) $(\%)$ & $6.2(0.8)$ & $5.6(0.5)$ & $6.8(0.7)$ & $6.0(0.8)$ & $5.4(0.2)$ & $6.7(0.7)$ & 0.340 & $<0.001$ \\
\hline Systolic blood pressure (mmHg) & $129.9(15.3)$ & $122.3(13.0)$ & $137.5(13.7)$ & $126.1(12.4)$ & $121.9(9.1)$ & $131.6(14.3)$ & 0.271 & $<0.001$ \\
\hline Diastolic blood pressure (mmHg) & $78.9(12.3)$ & $71.7(12.0)$ & $86.1(7.4)$ & $75.9(10.4)$ & $71.1(8.2)$ & $82.4(9.7)$ & 0.325 & $<0.001$ \\
\hline LDL cholesterol (mmol/L) & $2.51(0.70)$ & $2.71(0.81)$ & $2.32(0.53)$ & $2.70(0.82)$ & $2.99(0.82)$ & $2.31(0.67)$ & 0.403 & 0.002 \\
\hline HDL cholesterol (mmol/L) & $1.25(0.41)$ & $1.32(0.45)$ & $1.18(0.37)$ & $1.24(0.29)$ & $1.27(0.31)$ & $1.21(0.25)$ & 0.903 & 0.196 \\
\hline Total cholesterol (mmol/L) & $4.22(0.88)$ & $4.36(1.03)$ & $4.09(0.70)$ & $4.56(0.94)$ & $4.76(1.05)$ & $4.29(0.72)$ & 0.137 & 0.071 \\
\hline Triglycerides (mmol/L) & $1.01(0.62)$ & $0.72(0.25)$ & $1.30(0.74)$ & $1.36(0.70)$ & $1.10(0.56)$ & $1.71(0.73)$ & 0.004 & $<0.001$ \\
\hline 2-h OGTT glucose (mmol/L) & - & $5.2(1.1)$ & - & - & $5.1(1.3)$ & - & 0.727 & - \\
\hline Duration of T2D (years) & - & - & $2.73(1.3)$ & - & - & $3.10(0.98)$ & 0.298 & - \\
\hline Treatment with metformin (\%) & - & - & 70 & - & - & 55 & 0.320 & - \\
\hline
\end{tabular}

Data presented as mean (SD)

A two-way between-group ANOVA was used to analyse the dependent variables of ethnicity and glucose tolerance on the clinical characteristics $B A$ Black African, WE White European, $N G T$ normal glucose tolerance, $T 2 D$ type 2 diabetes, $B M I$ body mass index, DCCT Diabetes Control and Complications Trial, HbAlc glycated haemoglobin, $H D L$ high-density lipoprotein, IFCC International Federation of Clinical Chemistry, $L D L$ low-density lipoprotein, $O G T T$ oral glucose tolerance test 
Table 2 Metabolic measurements of participants by ethnicity and glucose tolerance

\begin{tabular}{|c|c|c|c|c|c|c|c|c|}
\hline & \multicolumn{3}{|l|}{ BA } & \multicolumn{3}{|l|}{ WE } & \multirow[t]{2}{*}{$P$ (ethnicity) } & \multirow{2}{*}{$\begin{array}{l}P \text { (gluc } \\
\text { tolerance) }\end{array}$} \\
\hline & $\begin{array}{l}\text { All } \\
(n=40)\end{array}$ & $\begin{array}{l}\text { NGT } \\
(n=20)\end{array}$ & $\begin{array}{l}\text { T2D } \\
(n=20)\end{array}$ & $\begin{array}{l}\text { All } \\
(n=41)\end{array}$ & $\begin{array}{l}\text { NGT } \\
(n=23)\end{array}$ & $\begin{array}{l}\text { T2D } \\
(n=18)\end{array}$ & & \\
\hline $\begin{array}{l}\text { Insulin } \\
\text { sensitivity } \\
\left(\mathrm{mg} \mathrm{m}^{-2}\right. \\
\left.\text { BSA min }{ }^{-1}\right) / \\
\left(\mathrm{pmol} \mathrm{L}^{-1}\right) \dagger\end{array}$ & $\begin{array}{l}0.41(0.32 \\
0.52)\end{array}$ & $\begin{array}{l}0.53(0.45 \\
0.62)\end{array}$ & $\begin{array}{l}0.31(0.21 \\
0.40)\end{array}$ & $\begin{array}{l}0.39(0.30 \\
0.51)\end{array}$ & $\begin{array}{l}0.53(0.41 \\
0.69)\end{array}$ & $\begin{array}{l}0.24(0.17 \text {, } \\
0.34)\end{array}$ & 0.413 & $<0.001$ \\
\hline $\begin{array}{l}\text { Insulin clear- } \\
\text { ance }(\mathrm{mL} \\
\mathrm{m}^{-2} \mathrm{BSA} \\
\left.\min ^{-1}\right) \dagger\end{array}$ & $\begin{array}{l}556.1(470.8, \\
657.1)\end{array}$ & $\begin{array}{l}681.1(601.3, \\
771.4)\end{array}$ & $\begin{array}{l}476.1(394.9, \\
574.0)\end{array}$ & $\begin{array}{l}686.6(593.8, \\
794.0)\end{array}$ & $\begin{array}{l}800.0(725.9, \\
881.5)\end{array}$ & $\begin{array}{l}568.9(430.3, \\
752.0)\end{array}$ & 0.011 & $<0.001$ \\
\hline $\operatorname{VAT}\left(\mathrm{cm}^{2}\right) \dagger$ & $\begin{array}{l}66.2(46.8, \\
66.2)\end{array}$ & $\begin{array}{l}46.9(34.2, \\
64.3)\end{array}$ & $\begin{array}{l}121.0(100.3, \\
146.0)\end{array}$ & $\begin{array}{l}108.3(81.6 \\
143.7)\end{array}$ & $\begin{array}{l}79.0(55.4 \\
112.5)\end{array}$ & $\begin{array}{l}184.4(148.3 \\
229.3)\end{array}$ & 0.001 & $<0.001$ \\
\hline $\begin{array}{l}\text { Adiponectin } \\
(\mathrm{mg} / \mathrm{L}) \dagger\end{array}$ & $\begin{array}{l}2.54(1.90, \\
3.40)\end{array}$ & $\begin{array}{l}3.18(2.42, \\
4.18)\end{array}$ & $\begin{array}{l}2.07(1.57, \\
2.72)\end{array}$ & $\begin{array}{l}3.62(3.05, \\
4.32)\end{array}$ & $4.39(3.72,5.20)$ & $\begin{array}{l}2.73(1.99, \\
3.73)\end{array}$ & 0.031 & 0.001 \\
\hline $\begin{array}{l}\text { TNF-a } \\
(\mathrm{ng} / \mathrm{L}) \dagger\end{array}$ & $\begin{array}{l}2.61(2.42, \\
2.81)\end{array}$ & $\begin{array}{l}2.26(1.92, \\
2.66)\end{array}$ & $\begin{array}{l}2.76(2.14, \\
3.55)\end{array}$ & $\begin{array}{l}2.74(2.21, \\
3.40)\end{array}$ & $\begin{array}{l}2.43(2.20 \\
2.67)\end{array}$ & $\begin{array}{l}2.91(2.54, \\
3.33)\end{array}$ & 0.481 & 0.016 \\
\hline IFN-y (ng/L) $\dagger$ & $\begin{array}{l}4.81(3.88, \\
5.96)\end{array}$ & $\begin{array}{l}4.85(4.02, \\
5.84)\end{array}$ & $\begin{array}{l}4.08(2.59 \\
6.42)\end{array}$ & $\begin{array}{l}4.85(4.16, \\
5.66)\end{array}$ & $4.29(3.62,5.07)$ & $\begin{array}{l}5.98(4.44, \\
8.04)\end{array}$ & 0.328 & 0.576 \\
\hline IL-6 (ng/L) $\dagger$ & $\begin{array}{l}0.93(0.80, \\
1.10)\end{array}$ & $\begin{array}{l}0.90(0.72, \\
1.12)\end{array}$ & $\begin{array}{l}1.02(0.77 \\
1.35)\end{array}$ & $\begin{array}{l}0.96(0.81, \\
1.14)\end{array}$ & $\begin{array}{l}0.88(0.71 \\
1.09)\end{array}$ & $\begin{array}{l}1.12(0.86, \\
1.44)\end{array}$ & 0.901 & 0.087 \\
\hline IL-8 (ng/L) $\dagger$ & $\begin{array}{l}8.51(7.18, \\
10.09)\end{array}$ & $\begin{array}{l}7.55(6.58, \\
8.67)\end{array}$ & $\begin{array}{l}10.55(7.77 \\
14.32)\end{array}$ & $\begin{array}{l}8.31(7.21 \text {, } \\
9.58)\end{array}$ & $7.99(6.82,9.35)$ & $\begin{array}{l}8.88(6.54, \\
12.07)\end{array}$ & 0.479 & 0.023 \\
\hline IL-10 (ng/L) $\dagger$ & $\begin{array}{l}0.74(0.58, \\
1.00)\end{array}$ & $\begin{array}{l}0.75(0.62, \\
0.92)\end{array}$ & $\begin{array}{l}0.72(0.42, \\
1.25)\end{array}$ & $\begin{array}{l}0.50(0.44, \\
0.58)\end{array}$ & $\begin{array}{l}0.53(0.44 \\
0.63)\end{array}$ & $\begin{array}{l}0.47(0.36, \\
0.61)\end{array}$ & 0.004 & 0.250 \\
\hline $\operatorname{VEGF}(\mathrm{ng} / \mathrm{L}) \dagger$ & $\begin{array}{l}79.2(59.4 \\
105.6)\end{array}$ & $\begin{array}{l}\text { 62.1 (42.6, } \\
90.6)\end{array}$ & $\begin{array}{l}104.5(65.9 \\
165.5)\end{array}$ & $\begin{array}{l}62.8(49.2, \\
80.1)\end{array}$ & $\begin{array}{l}51.8(37.4, \\
71.7)\end{array}$ & $\begin{array}{l}86.8(62.3, \\
120.9)\end{array}$ & 0.560 & 0.002 \\
\hline
\end{tabular}

All biomarkers measured during fasting

Data presented as mean (SD) or geometric mean (95\% CI) for logged data

$\dagger$ BSA, body surface area. IL, interleukin; VAT, visceral adipose tissue; VEGF, vascular endothelial growth factor; TNF- $\mathbf{a}$, tumour necrosis factor alpha; IFN-y, interferon gamma. Data from subjects included in this study have been previously published in [22-24]. A two-way betweengroup ANOVA was used to analyse the dependent variables of ethnicity and glucose tolerance on the outcome measures

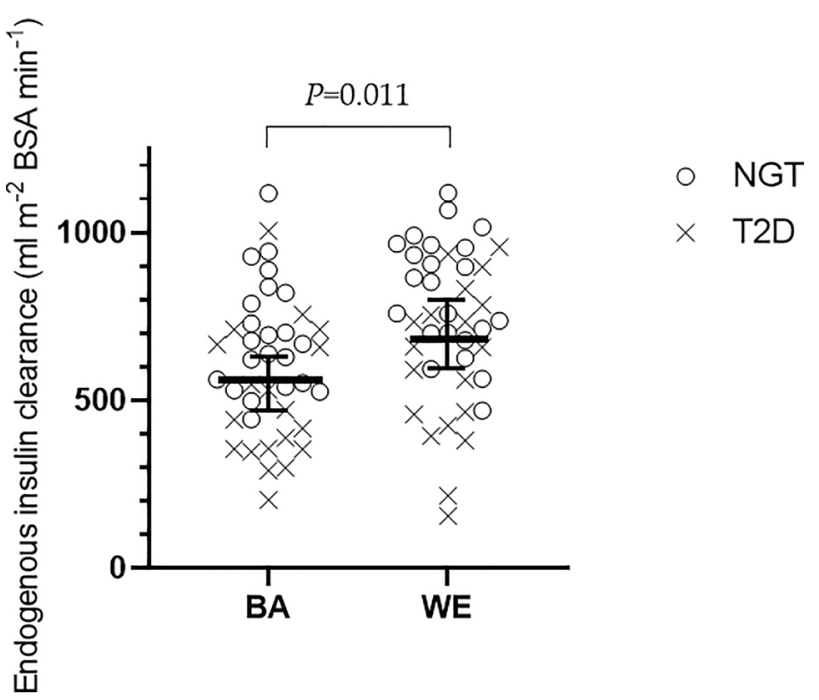

Fig. 1 Endogenous insulin clearance by ethnicity and glucose tolerance status. BA, Black African; WE, white European; NGT, normal glucose tolerance; T2D, type 2 diabetes. Data shown as median $(95 \%$ confidence intervals)
The BA men in this study exhibited the metabolic features characteristic of their ethnic group, including lower visceral fat, lower adiponectin and lower insulin clearance compared with WE men of similar age and BMI. A body of literature proposes that low insulin clearance in BA populations is secondary to insulin resistance. Lorenzo et al. presented data showing that ethnic differences in the metabolic clearance rate of insulin (MCRI) of African-American (versus Hispanic and White American) participants could be entirely explained by insulin resistance and adiposity [7]. However, in our study, by contrast, ethnicity determined insulin clearance independently of insulin sensitivity, BMI and visceral fat. The discrepancy in findings may be due to the methodologies used to measure insulin clearance. The MCRI measures the clearance of peripherally infused exogenous insulin, rather than the clearance of endogenous insulin, the latter being secreted directly into the portal vein and undergoing extraction by the liver prior to entering the systemic circulation [28]. Our measurement of insulin clearance 
Table 3 Relationships between insulin clearance and adipocytokines using Pearson's correlation

\begin{tabular}{lcrr}
\hline & \multicolumn{1}{c}{ BA $(n=40)$} & WE $(n=41)$ & All $(n=81)$ \\
\hline Adiponectin (mg/L) & $r=0.53, P=0.001$ & $r=0.31, P=0.059$ & $r=0.46, P<0.001$ \\
TNF-a (ng/L) & $r=-0.17, P=0.32$ & $r=-0.42, P=0.008$ & $r=-0.24, P=0.037$ \\
IFN-y (ng/L) & $r=0.23, P=0.27$ & $r=-0.14, P=0.42$ & $r=0.04, P=0.79$ \\
IL-6 (ng/L) & $r=0.05, P=0.75$ & $r=-0.26, P=0.10$ & $r=-0.10, P=0.37$ \\
IL-8 (ng/L) & $r=-0.05, P=0.75$ & $r=-0.14, P=0.39$ & $r=-0.11, P=0.32$ \\
IL-10 (ng/L) & $r=0.14, P=0.41$ & $r=0.02, P=0.93$ & $r=0.01, P=0.95$ \\
VEGF (ng/L) & $r=-0.08, P=0.63$ & $r=0.04, P=0.83$ & $r=-0.04, P=0.95$ \\
\hline
\end{tabular}

All $\mathrm{r}$ and $P$ values for correlation with endogenous insulin clearance
Table 4 Multiple regression analysis of predictors of insulin clearance $\left(\mathrm{mL} \mathrm{m}^{-2}\right.$ BSA $\left.\mathrm{min}^{-1}\right)$

\begin{tabular}{lllc}
\hline Independent variables & $\begin{array}{l}\text { Regression } \\
\text { coefficient }\end{array}$ & $95 \%$ CI & $P$ value \\
\hline MODEL 1: $R^{2}=0.418$ & & & \\
Ethnicity (BA-WE) $^{\mathrm{a}}$ & -96 & -180 to -12 & 0.025 \\
Body mass index $^{\mathrm{b}}$ & -36.4 & -70.8 to -2.0 & 0.038 \\
Insulin sensitivity $^{\mathrm{b}}$ & 9.0 & $0.2-17.8$ & 0.046 \\
Plasma adiponectin $^{\mathrm{b}}$ & 7.9 & $0.5-15.3$ & 0.036 \\
${\text { MODEL 2: } R^{2}=0.434}$ & & \\
Ethnicity (BA-WE) $^{\mathrm{a}}$ & -99 & -196 to -1 & 0.047 \\
Insulin sensitivity $^{\mathrm{b}}$ & 38.9 & $18.0-59.8$ & $<0.001$ \\
Plasma adiponectin $^{\mathrm{b}}$ & 20.4 & $2.2-38.6$ & 0.029 \\
Plasma TNF- $^{2}$ & -6.3 & -35.7 to 23.2 & 0.67 \\
Age $^{\mathrm{c}}$ & 1.6 & -40.4 to 43.6 & 0.94 \\
Visceral adipose tissue $^{\mathrm{b}}$ & 5.1 & -16.7 to 27.0 & 0.64 \\
\hline
\end{tabular}

${ }^{a}$ Regression coefficient is adjusted difference in mean insulin clearance, BA-WE ${ }^{\text {b }}$ Variable is log-transformed. Regression coefficient and $95 \% \mathrm{CI}$ are scaled so that each is the adjusted change in insulin clearance for a $10 \%$ increase in that variable

${ }^{c}$ Regression coefficient is the adjusted change in insulin clearance per 10 -year increase in age

takes account of first-pass hepatic insulin extraction, which is not captured by the MCRI. It is known that the MCRI is poorly correlated with both directly measured hepatic insulin extraction in animal models [29] and surrogate measures of hepatic insulin clearance derived from the hyperglycaemic clamp [30]. While hepatic insulin clearance is lower in BA in comparison with WE, extra-hepatic clearance is similar [2] and both these processes appear to be differentially regulated [5, 20]. Therefore, the MCRI may not be a wholly representative measure of insulin clearance when comparing these ethnic groups.

It has been argued that low insulin clearance is a primary determinant of peripheral insulin levels rather than a compensatory mechanism for insulin resistance $[8,31]$. Our findings support this, as endogenous insulin clearance in the BA subjects remained low even when adjustments for insulin sensitivity were made. We have previously shown that low insulin clearance compensates for postprandial insulin secretion deficiencies in BA subjects and therefore may act as a protective mechanism [24]. However, under conditions where insulin secretion rates are excessively stimulated (such as during the hyperglycaemic clamp), low insulin clearance leads to a marked hyperinsulinaemia [27]. Chronic hyperinsulinaemia is thought to be metabolically deleterious, predisposing to insulin resistance, beta-cell stress and glucose intolerance [32]. Therefore, a metabolic characteristic which under some conditions may be an evolutionary advantage, relieving the demand on the beta cell to upregulate insulin secretion, may in other environments prove unfavourable. As this was not a longitudinal study, it cannot provide evidence of a causative relationship between low insulin clearance and T2D. However, the significantly lower insulin clearance in NGT BA men, in the presence of comparable insulin sensitivity to their WE counterparts, supports the hypothesis that impairments in insulin clearance precede the development of other metabolic abnormalities in the progression to glucose intolerance. Therefore, manipulation of hepatic insulin clearance may offer a novel therapeutic target for T2D in this high-risk ethnic population.

Much remains to be understood in relation to insulin clearance and its regulation; therefore, any interpretations of these data are necessarily speculative. Although insulin resistance does not account for low insulin clearance in BA men, we did not find that ethnic differences in cytokine admixture provided an alternative explanation. Consistent with the literature, where various inflammatory markers have been linked to impaired insulin clearance $[12,13]$, we found a negative correlation between TNF- $\alpha$ and insulin clearance. However, in agreement with others, this did not persist following correction for insulin sensitivity and adiposity [13]. Thus, subclinical inflammation per se does not appear to directly affect insulin clearance but accompanies it through associations with other features of metabolic dysfunction. It must be acknowledged that in a small sample, the failure to observe a relationship between two variables does not mean that a relationship is absent, and further work into the link between inflammation and insulin clearance is indicated. 
On the other hand, adiponectin was associated with increased insulin clearance independently of insulin sensitivity and adiposity. Higher adiponectin concentrations are associated with a reduced risk of T2D in BA subjects [33, 34], which is thought to be mediated via adiponectin's beneficial effects on both insulin sensitivity [34] and beta-cell proliferation and survival. However, the importance of adiponectin as an independent modulator of insulin clearance in BA populations has never been examined. Adiponectin receptors are abundantly expressed in the liver, and adiponectin has pleiotropic effects on hepatic metabolism, including suppression of hepatic glucose production and lipogenesis [35]; but adiponectin's role in hepatic insulin clearance has been little explored. While an association between adiponectin and insulin clearance has been previously observed $[19,20]$, this is the first time a relationship has been demonstrated independently of adiposity and insulin sensitivity. The findings of this study suggest that an examination of adiponectin signalling and hepatic insulin clearance is warranted at a molecular level, in order to investigate whether adiponectin is an active player in the mechanisms of clearance.

While low adiponectin concentrations appear to be an important factor, they do not entirely explain the low insulin clearance of the BA men. Low insulin clearance has been demonstrated in a wide variety of BA subjects, including healthy men [27] and women [36], obese adolescents [37] and adults with T2D [38]. The highly conserved nature of this trait is well illustrated by Osei et al. who demonstrated that while African-Americans, native Ghanaians and Ghanaian immigrants to the USA have similar rates of insulin clearance to each other, all three BA groups have lower insulin clearance compared with White Americans [39]. The consistency of this observation in disparate BA populations, regardless of sex, age or indigenous or diasporic origin, is suggestive of an inherent rather than environmental cause, although to date no responsible genetic variant in BA populations has been identified.

While the mechanisms underlying this ethnic characteristic remain elusive, given that insulin clearance appears to be regulated in the BA men independently of insulin's action on glucose uptake, we hypothesise that specific signalling pathways may be involved. One study has identified lower insulin-degrading enzyme (IDE) activity in the liver tissue of African-Americans [40] as a possible explanation, although the importance of IDE in the regulation of hepatic insulin clearance has been questioned [41, 42]. Other potential avenues of interest include the role of carcinoembryonic antigen-related cell adhesion molecule-1 (CEACAM-1) [28], zinc ion transport [43] and the signals which determine rates of retro-endocytosis (by which a variable proportion of receptor-bound, internalised insulin undergoes rapid exocytosis from the hepatocyte and is returned back to the circulation [44]). The findings of this study present an appeal to basic scientists to re-examine the intracellular pathways of insulin trafficking and degradation, an area which needs further exploration.

The strengths of this study are its measurement of endogenous as opposed to exogenous insulin clearance and the use of the reference-standard hyperinsulinaemic-euglycaemic clamp to measure insulin sensitivity. The use of magnetic resonance quantification of visceral adipose tissue provided a more accurate measure of adiposity than BMI alone. Furthermore, the subjects were tightly characterised, with the BA men of strict West African ancestry. In terms of limitations, the modelled measure of endogenous insulin clearance does not enable differentiation between hepatic and extra-hepatic insulin clearance. The assumption is made that whole-body clearance is a good proxy of hepatic insulin clearance, as hepatic insulin clearance is responsible for around $80 \%$ of whole-body clearance [45]. However, others have found that in BA populations, the proportion of total endogenous insulin clearance attributable to the liver may be as little as 30\% [5]. The inability to distinguish between the two processes means that the specific effect of ethnicity in relation to hepatic insulin clearance - and its relationships with hepatic insulin sensitivity — could not be isolated. Our small sample size means that only large differences in the mean could be detected. Furthermore, our study is a secondary exploratory analysis, so we have not adjusted for multiple testing. Hence, our findings need replicating in other larger datasets. Finally, these findings apply to adult men only; therefore, they cannot necessarily be generalised to female or child/adolescent populations.

In conclusion, in a cohort of BA men, neither insulin resistance, inflammatory cytokines nor adiponectin concentrations appear to fully account for their low insulin clearance. We hypothesise that an inherent ethnic variation in intracellular insulin degradation pathways is responsible for this metabolic phenomenon, one that has evolved due to adaptive advantage but, in accordance with emerging hypotheses, has potentially deleterious effects on glucose tolerance in the setting of excessive beta-cell stimulation. The identification and manipulation of such pathways offer a novel avenue of investigation for the prevention and management of T2D.

Acknowledgements The authors thank Cynthia Mohandas, Andrew Pernet, Bula Wilson and Marcia Henderson (Diabetes Research Group, King's College Hospital, UK) for assisting with the metabolic assessments; Geoff Charles-Edwards (King's College London, UK) for assistance with magnetic resonance imaging interpretation; Anne-Catherine Perz (King's College London, UK), Daniel Curtis (University of Surrey, UK) and Tracy Dew (Affinity Biomarkers Lab, UK) for assistance with sample processing and laboratory analysis; Elka Giemsa (CRF Manager, King's College Hospital, UK) for accommodating the participant visits; the staff of the Clinical Research Facility at King's College Hospital for help in performing the studies; and the study participants 
for their time and commitment. Louise Goff is the guarantor of this work, had full access to all the data and takes full responsibility for the integrity of the data and the accuracy of data analysis.

Author contributions LMG, SAA, AMU and JLP were involved in conceptualisation; LMG, SAA, AMU, JLP and RCB were involved in methodology; ML, OB, OH, MLB and FSM were involved in formal analysis; ML, OB, OH and FSM were involved in investigation; ML was involved in writing - original draft preparation; all authors were involved in writing - review and editing; LMG, SAA, AMU, RCB and MLB were involved in supervision; and LMG, SAA, AMU and JLP were involved in funding acquisition. All authors have read and agreed to the published version of the manuscript. JLP was supported by the NIHR Biomedical Research Centre based at Guy's and St Thomas' NHS Foundation Trust and King's College London and is an NIHR Senior Investigator.

Funding This research was funded by Diabetes UK, Grant Numbers $12 / 0004473$ and $14 / 0004967$. The funders had no role in the design of the study; in the collection, analyses or interpretation of data; in the writing of the manuscript; or in the decision to publish the results.

Data availability Data are available upon request from the corresponding author.

\section{Declarations}

Conflict of interest The authors declare no conflict of interest.

Ethical approval The SouL-DeEP study was approved by the London Bridge National Research Ethics Committee (15/LO/1121 and 12/ LO/1859).

Informed consent All subjects provided written informed consent prior to participation.

Open Access This article is licensed under a Creative Commons Attribution 4.0 International License, which permits use, sharing, adaptation, distribution and reproduction in any medium or format, as long as you give appropriate credit to the original author(s) and the source, provide a link to the Creative Commons licence, and indicate if changes were made. The images or other third party material in this article are included in the article's Creative Commons licence, unless indicated otherwise in a credit line to the material. If material is not included in the article's Creative Commons licence and your intended use is not permitted by statutory regulation or exceeds the permitted use, you will need to obtain permission directly from the copyright holder. To view a copy of this licence, visit http://creativecommons.org/licenses/by/4.0/.

\section{References}

1. Piccinini F, Polidori DC, Gower BA, Fernandez JR, Bergman RN (2018) Dissection of hepatic versus extra-hepatic insulin clearance: ethnic differences in childhood. Diab Obes Metab 20(12):2869-2875

2. Piccinini F, Polidori DC, Gower BA, Bergman RN (2017) Hepatic but not extrahepatic insulin clearance is lower in African American Than in European American women. Diabetes 66(10):2564-2570

3. Duckworth WC, Bennett RG, Hamel FG (1998) Insulin degradation: progress and potential. Endocr Rev 19(5):608-624
4. Kim SH, Reaven GM (2016) Insulin clearance: an underappreciated modulator of plasma insulin concentration. J Investig Med 64(7):1162-1165

5. Polidori DC, Bergman RN, Chung ST, Sumner AE (2016) Hepatic and extrahepatic insulin clearance are differentially regulated: results from a novel model-based analysis of intravenous glucose tolerance data. Diabetes 65(6):1556-1564

6. Haffner SM, D'Agostino R, Saad MF, Rewers M, Mykkanen L, Selby J et al (1996) Increased insulin resistance and insulin secretion in nondiabetic African-Americans and Hispanics compared with non-Hispanic whites. Insulin Resistance Atherosclerosis Stud Diab 45(6):742-748

7. Lorenzo C, Hanley AJ, Wagenknecht LE, Rewers MJ, Stefanovski D, Goodarzi MO et al (2013) Relationship of insulin sensitivity, insulin secretion, and adiposity with insulin clearance in a multiethnic population: the insulin resistance atherosclerosis study. Diabetes Care 36(1):101-103

8. Bergman RN, Piccinini F, Kabir M, Kolka CM, Ader M (2019) Hypothesis: role of reduced hepatic insulin clearance in the pathogenesis of type 2 diabetes. Diabetes 68(9):1709-1716

9. Watada H, Tamura Y (2017) Impaired insulin clearance as a cause rather than a consequence of insulin resistance. J Diabetes Investig $8(6): 723-725$

10. Lee CC, Haffner SM, Wagenknecht LE, Lorenzo C, Norris JM, Bergman RN et al (2013) Insulin clearance and the incidence of type 2 diabetes in Hispanics and African Americans: the IRAS Family Study. Diabetes Care 36(4):901-907

11. Lamprinou A, Machann J, Schick F, Eckstein SS, Man CD, Visentin $\mathrm{R}$ et al (2020) Hepatic insulin clearance is not driven by liver fat but by systemic inflammation: a mendelian randomization study. Diabetes 69(1):1856

12. Semnani-Azad Z, Johnston LW, Lee C, Retnakaran R, Connelly PW, Harris SB et al (2019) Determinants of longitudinal change in insulin clearance: the prospective metabolism and islet cell evaluation cohort. BMJ Open Diab Res Care 7(1):e000825

13. Lee CC, Lorenzo C, Haffner SM, Wagenknecht LE, Festa A, Goodarzi MO et al (2013) The association of inflammatory and fibrinolytic proteins with 5 year change in insulin clearance: the insulin resistance atherosclerosis study (IRAS). Diabetologia 56(1):112-120

14. Yao S, Hong CC, Ruiz-Narváez EA, Evans SS, Zhu Q, Schaefer BA et al (2018) Genetic ancestry and population differences in levels of inflammatory cytokines in women: role for evolutionary selection and environmental factors. PLoS Genet 14(6):e1007368

15. Khera A, McGuire DK, Murphy SA, Stanek HG, Das SR, Vongpatanasin W et al (2005) Race and gender differences in C-reactive protein levels. J Am Coll Cardiol 46(3):464-469

16. Bacha F, Saad R, Gungor N, Arslanian SA (2005) Does adiponectin explain the lower insulin sensitivity and hyperinsulinemia of African-American children? Pediatr Diab 6(2):100-102

17. Degawa-Yamauchi M, Dilts JR, Bovenkerk JE, Saha C, Pratt JH, Considine RV (2003) Lower serum adiponectin levels in AfricanAmerican boys. Obes Res 11(11):1384-1390

18. Hulver MW, Saleh O, MacDonald KG, Pories WJ, Barakat HA (2004) Ethnic differences in adiponectin levels. Metab Clin Exp 53(1):1-3

19. Okura T, Fujioka Y, Nakamura R, Anno M, Ito Y, Kitao S et al (2020) Hepatic insulin clearance is increased in patients with high HbA1c type 2 diabetes: a preliminary report. BMJ Open Diab Res Care 8(1):e001149

20. Utzschneider KM, Kahn SE, Polidori DC (2019) Hepatic insulin extraction in NAFLD is related to insulin resistance rather than liver fat content. J Clin Endocrinol Metab 104(5):1855-1865

21. Kabir M, Iyer MS, Richey JM, Woolcott OO, Asare Bediako I, Wu Q et al (2015) CB1R antagonist increases hepatic insulin 
clearance in fat-fed dogs likely via upregulation of liver adiponectin receptors. Am J Physiol Endocrinol Metab 309(8):E747-E758

22. Mohandas C, Bonadonna R, Shojee-Moradie F, Jackson N, Boselli L, Alberti K et al (2018) Ethnic differences in insulin secretory function between black African and white European men with early type 2 diabetes. Diabetes Obes Metab 20(7):1678-1687

23. Hakim O, Bello O, Ladwa M, Peacock JL, Umpleby AM, CharlesEdwards G et al (2020) The link between obesity and inflammatory markers in the development of type 2 diabetes in men of black african and white european ethnicity. Nutrients 12(12):3796

24. Ladwa M, Bello O, Hakim O, Shojaee-Moradie F, Boselli ML, Charles-Edwards G et al (2021) Ethnic differences in beta cell function occur independently of insulin sensitivity and pancreatic fat in black and white men. BMJ Open Diab Res Care 9(1):e002034

25. Navalesi R, Pilo A, Ferrannini E (1978) Kinetic analysis of plasma insulin disappearance in nonketotic diabetic patients and in normal subjects: a tracer study with $125 \mathrm{I}$-insulin. J Clin Invest 61(1):197-208

26. Hamley S, Kloosterman D, Duthie T, Dalla Man C, Visentin R, Mason SA et al (2019) Mechanisms of hyperinsulinaemia in apparently healthy non-obese young adults: role of insulin secretion, clearance and action and associations with plasma amino acids. Diabetologia 62(12):2310-2324

27. Ladwa M, Bello O, Hakim O, Shojaee-Moradie F, Boselli L, Charles-Edwards G et al (2020) Insulin clearance as the major player in the hyperinsulinaemia of black African men without diabetes. Diab Obesity Metab 22:1808

28. Najjar SM, Perdomo G (2019) Hepatic Insulin Clearance: Mechanism and Physiology. Physiology (Bethesda) 34(3):198-215

29. Asare-Bediako I, Paszkiewicz RL, Kim SP, Woolcott OO, Kolka CM, Burch M et al (2018) Assessment of hepatic insulin extraction from in vivo surrogate methods of insulin clearance measurement. Am J Physiol Endocrinol Metab 315(4):E605-E612

30. Uwaifo GI, Nguyen TT, Keil MF, Russell DL, Nicholson JC, Bonat SH et al (2002) Differences in insulin secretion and sensitivity of Caucasian and African American prepubertal children. J Pediatr 140(6):673-680

31. Bojsen-Møller KN, Lundsgaard A-M, Madsbad S, Kiens B, Holst JJ (2018) Hepatic insulin clearance in regulation of systemic insulin concentrations: role of carbohydrate and energy availability. Diabetes 67(11):2129-2136

32. Corkey BE (2012) Banting lecture 2011: hyperinsulinemia: cause or consequence? Diabetes 61(1):4-13

33. Bidulescu A, Dinh PC, Sarwary S, Forsyth E, Luetke MC, King DB et al (2020) Associations of leptin and adiponectin with incident type 2 diabetes and interactions among African Americans: the Jackson heart study. BMC Endocr Disord 20(1):31

34. Hanley AJ, Wagenknecht LE, Norris JM, Bergman R, Anderson A, Chen YI et al (2011) Adiponectin and the incidence of type 2 diabetes in hispanics and African Americans: the IRAS family study. Diabetes Care 34(10):2231-2236
35. Combs TP, Marliss EB (2014) Adiponectin signaling in the liver. Rev Endocr Metab Disord 15(2):137-147

36. Chung ST, Galvan-De La Cruz M, Aldana PC, Mabundo LS, DuBose CW, Onuzuruike AU et al (2019) Postprandial insulin response and clearance among black and white women: the federal women's study. J Clin Endocrinol Metab 104(1):181-92

37. Tricò D, Galderisi A, Mari A, Polidori D, Galuppo B, Pierpont B et al (2020) Intrahepatic fat, irrespective of ethnicity, is associated with reduced endogenous insulin clearance and hepatic insulin resistance in obese youths: a cross-sectional and longitudinal study from the Yale Pediatric NAFLD cohort. Diab Obes Metab 22(9):1628-1638

38. Rasouli N, Younes N, Utzschneider KM, Inzucchi SE, Balasubramanyam A, Cherrington AL et al (2020) Association of baseline characteristics with insulin sensitivity and $\beta$-cell function in the glycemia reduction approaches in diabetes: a comparative effectiveness (GRADE) study cohort. Diabetes Care 44:340

39. Osei K, Schuster DP, Owusu SK, Amoah AG (1997) Race and ethnicity determine serum insulin and C-peptide concentrations and hepatic insulin extraction and insulin clearance: comparative studies of three populations of West African ancestry and white Americans. Metabolism 46(1):53-58

40. Fosam A, Sikder S, Abel BS, Tella SH, Walter MF, Mari A et al (2020) Reduced insulin clearance and insulin-degrading enzyme activity contribute to hyperinsulinemia in African Americans. $\mathbf{J}$ Clin Endocrinol Metab 105(4):e1835-e1846

41. Villa-Pérez P, Merino B, Fernández-Díaz CM, Cidad P, Lobatón $\mathrm{CD}$, Moreno A et al (2018) Liver-specific ablation of insulindegrading enzyme causes hepatic insulin resistance and glucose intolerance, without affecting insulin clearance in mice. Metab Clin Exp 88:1-11

42. Merino B, Fernández-Díaz CM, Parrado-Fernández C, GonzálezCasimiro CM, Postigo-Casado T, Lobatón CD et al (2020) Hepatic insulin-degrading enzyme regulates glucose and insulin homeostasis in diet-induced obese mice. Metab Clin Exp 113:154352

43. Tamaki M, Fujitani Y, Hara A, Uchida T, Tamura Y, Takeno K et al (2013) The diabetes-susceptible gene SLC30A8/ZnT8 regulates hepatic insulin clearance. J Clin Investig 123(10):4513-4524

44. Levy JR, Olefsky JM (1987) The trafficking and processing of insulin and insulin receptors in cultured rat hepatocytes. Endocrinology 121(6):2075-2086

45. Ferrannini E, Wahren J, Faber OK, Felig P, Binder C, DeFronzo RA (1983) Splanchnic and renal metabolism of insulin in human subjects: a dose-response study. Am J Physiol 244(6):E517-E527

Publisher's Note Springer Nature remains neutral with regard to jurisdictional claims in published maps and institutional affiliations. 